\title{
Effects of Verbal and Physical Violence by Patient Companions on Female Nurses and Their Health
}

\author{
Masoumeh Shohan, ${ }^{1}$ Gholamreza Noori, ${ }^{2}$ Elham Mohammadyari, ${ }^{3}$ Aminollah Vasigh, ${ }^{4}$ Behrang \\ Kazeminezhad, ${ }^{5}$ and Hamed Tavan ${ }^{6,}$ \\ ${ }^{1}$ Department of Nursing, Faculty of Allied Medical, Ilam University of Medical Sciences, Ilam, Iran \\ ${ }^{2}$ Department of Medicine, Faculty of Medicine, Ilam University of Medical Sciences, Ilam, Iran \\ ${ }^{3}$ Department of Cardiology, Faculty of Medicine, Ilam University of Medical Sciences, Ilam, Iran \\ ${ }^{4}$ Assistant Professor of Anesthesiology, Ilam University of Medical Sciences, Ilam, Iran \\ ${ }^{5}$ Clinical Research Development Center at Shahidmodarres Hospital, Department of Pathology, Shahid Beheshti University of Medical Sciences, Tehran, Iran \\ ${ }^{6}$ Department of Nursing, Psychosocial Injuries Research Center, Ilam University of Medical Sciences, Ilam, Iran \\ "Corresponding author: Hamed Tavan, Clinical Research Development Center at Shahidmodarres Hospital, Department of Pathology, Shahid Beheshti University of Medical \\ Sciences, Tehran, Iran. Tel: +98- 9187474221, E-mail: hamedtavan@gmail.com
}

Received 2017 June 01; Revised 2017 June 15; Accepted 2017 September 05.

Keywords: Verbal Violence, Physical Violence, Nurses

\section{Dear Editor,}

Workplace violence refers to any nonverbal threatening behavior (including pointing finger, staring, and clenching fists) (1), verbal threat (including angry voice and tone, shouting, screaming, and swearing) (2), or physical assault (including inappropriate touching, pushing, kicking, kicking a knife, and shooting) (3).

A questionnaire was used for examining physical violence by patient companions towards female nurses at training hospitals of Ilam, Iran $(4,5)$, as women are more vulnerable to workplace violence and their population is high at hospitals. Moreover, considering their high sensitivity, violence has many effects on their personal life. Accordingly, we investigated workplace violence towards female nurses. A total of 120 female nurses working in hospitals were randomly selected from different working shifts and asked about exposure to physical violence for a month (January 2017).

In this study, nurses were assured that the information would remain confidential and would be only used for publication in scientific communities. Participation in the study was voluntary in a way that subjects could withdraw at any stage of the research. All the participants agreed to complete the questionnaires. The results showed that physical violence by patient companions against female nurses was $10.71 \%$, and the vulnerable age group was 30 - 40 years (22.95\%).

Based on the findings, $31.14 \%$ of nurses in the age group of 30 - 40 years were mostly threatened by cold weapons, while $68.9 \%$ of nurses declared no cases of violence. During interviews with nurses, $11.8 \%$ stated that physical violence had affected their health, and $44.2 \%$ claimed that their mental health had been disrupted by threats with melee weapons. Compromised physical or even mental health of nurses can result in a lower quality of task performance and reduce nurses' efficiency in patient care.

Fear, anxiety, and depression decrease physical and mental strength, and acute stress disorders result from workplace violence (3-5). Accordingly, the causes of violence should be determined, and to reduce violence, a secure environment should be provided and different visiting hours should be scheduled in each ward. Moreover, nurses may become more motivated by increasing the number of personnel in working shifts and promoting their salary and benefits.

Besides establishing courses for the personnel on how to communicate with patients and their companions, proper reactions towards violence should be encouraged. Although it is not possible to completely eliminate violence, compliance with the mentioned suggestions can reduce the occurrence of violence $(4,5)$. Finally, study of the statistical significance of risk factors for mental diseases, physical assault, and nurses' treatment are interesting topics for future investigations.

\section{Acknowledgments}

Hereby, we would like to express our gratitude to the journal.

\section{Footnote}

Authors' Contribution: All authors equally contributed to the study. 


\section{References}

1. Mozafari M, Tavan H. Survey of violence against nursing in the Ilam training hospitals at 2012. Jlam Univ Med Sci. 2013;21(2):152-60.

2. Sohrabzadeh M, Menati R, Tavan H, Mozafari M, Menati W. Survey on patient against female nurses and lack of reporting aggressive event in Ilam hospitals at 2012 [In Persian]. Iran Occup Health J. 2015;12(1):4755.
3. Sohrabzadeh M, Menati R, Tavan H. Workplace violence against female nurses: a survey in critical care units. Int J Hospital Res. 2014;3(2):55-62.

4. Aivazi AA, Tavan H. Prevalence of conceived violence against nurses at educational hospitals of Ilam, Iran, 2012. Int J Afr Nur Sci. 2015;2:65-8. doi: 10.1016/j.ijans.2015.04.001.

5. Aivazi AA, Menati W, Tavan H, Navkhasi S, Mehrdadi A. Patients' bill of rights and effective factors of workplace violence against female nurses on duty at Ilam teaching hospitals. J Inj Violence Res. 2017;9(1) doi: 10.5249/jivr.v9i1.779. [PubMed: 28039684]. 